doi:10.17659/01.2017.0072

Journal of Case Reports 2017;7(3):270-273

\title{
A Novel Cytogenetic Variant Translocation in Acute Myeloid Leukemia
}

\author{
Monika V Patel $^{1}$, Salil N Vaniawala ${ }^{2}$, Pankaj K Gadhia ${ }^{2}$ \\ 1,2 JJTU University, Rajasthan, India; ${ }^{2}$ Molecular Cytogenetic Unit, S.N. Gene Laboratory and Research Centre, Surat, India.
}

\section{Corresponding Author:}

Dr. Pankaj K. Gadhia

Email: pankajkgadhia@gmail.com

This is an Open Access article distributed under the terms of the Creative Commons Attribution License (creativecommons.org/ licenses/by/3.0).

Received : June 12, 2017

Accepted : July 10, 2017

Published : July 30, 2017

\begin{abstract}
Background: Acute myeloid leukemia (AML) is a heterogeneous group of malignant neoplasm of hematopoietic disorders characterized by an abnormal proliferation of myeloid precursors. Variant forms of classic translocation $\mathrm{t}(8 ; 21)$ are uncommon, and either third or fourth chromosomes accounts for approximately 3-4\% in acute myeloid leukemia. Case Report: We report a rare case of a 16-year old male having $\mathrm{t}(8 ; 19 ; 21)$ (q22;q13;q22) associated with loss of sex chromosome. To the best of our knowledge, only few cases are described with variants of $\mathrm{t}(8 ; 21)$ in AML and we first time report the involvement of 19q13 breakpoint region in AML. Conclusion: Translocation $\mathrm{t}(8 ; 19 ; 21)$ ( $\mathrm{q} 22 ; \mathrm{q} 13 ; \mathrm{q} 22)$ is a novel, rare but recurrent variant translocation of $\mathrm{t}(8 ; 21)$. Due to the rarity of this translocation future accumulation of similar cases needed to evaluate clinical as well as prognostic and biological features.
\end{abstract}

Keywords: Chromosomes, Cytogenetics, Karyotyping, Neoplasms, Sex Chromosome, Translocation.

\section{Introduction}

Acute myeloid leukemia (AML) is a heterogeneous group of malignant neoplasm of hematopoietic disorders characterized by an abnormal proliferation of myeloid precursors [1]. Conventional cytogenetic analysis can be used for identification recurrent chromosomal abnormality and thereby it serves as one of the most important diagnostic and prognostic markers in AML patients. Variants of $\mathrm{t}(8 ; 21)$ involving chromosome 8,21 and other chromosomes account for approximately $3-4 \%$ in AML associated $\mathrm{t}(8 ; 21)[2,3]$.

The translocation $\mathrm{t}(8 ; 21)(\mathrm{q} 22 ; \mathrm{q} 22)$ is recurrent chromosomal aberrations typically found in AML and is closely associated with French American British (FAB) classification M2 subtype and less frequently in M1 or M4 subtype [4]. In addition, the complex cytogenetic variants of this translocation are the three-way translocations involving regions of $8 \mathrm{q} 22,21 \mathrm{q} 22$ and third chromosome [5]. Molecularly, the $t(8 ; 21)$ leads to fusion of AML1 (RUNX1) gene located at 21q22 to ETO(RUNX1T1) gene located at 8q22, generating a chimeric AML1/ETO fusion gene on derivative chromosome 8 (der8) [2]. However, Grimwade et al. [6] suggested that the patients positive for this chimeric fusion are known to have a favorable prognosis. In addition, the formation of AML1/ETO chimeric fusion gene are frequently accompanied by additional chromosomal changes such as loss of sex chromosome and del(9) (q22) [7]. The frequency is approximately $10-15 \%$ of all such cases [8].

Moreover, the variants in some cases present as hidden translocation, in such cases it is difficult to identify the $t(8 ; 21)$ by conventional cytogenetic analysis [4]. Here, we describe a case of three-way complex translocation $\mathrm{t} t(8 ; 19 ; 21)$ (q22;q13;q22) associated with additional chromosomal abnormalities including loss of $\mathrm{Y}$ chromosome. 


\section{Case Report}

A 16 years old male with no significant past medical history was referred for cytogenetic analysis. His complete blood counts showed a hemoglobin level $4.4 \mathrm{~g} / \mathrm{dL}$, a platelet count of $97000 / \mu \mathrm{L}$ and white blood cell count of $8400 / \mu \mathrm{L}$ with $37.0 \%$ neutrophils, $18.0 \%$ lymphocyte, and $45 \%$ blasts. The initial results of the karyotype of this patient were $45, \quad X,-Y, t(8 ; 19 ; 21)(q 22 ; q 13 ; q 22)$ in all metaphases analyzed.

Conventional cytogenetic technique was performed on 24 hours unstimulated short term culture of bone marrow cells. The cells were grown in culture medium Marrowmax (GIBCO) supplemented with $20 \%$ of FBS (fetal bovine serum). The colcemid was added for 30 minutes followed by $\mathrm{KCL}(75 \mathrm{mM})$ at room temperature for 27 minutes and Carnoys fixative was used to fix the cells for four times. Slides were stained with GTG banding technique [9]. GTG banded metaphase from each culture was analyzed and karyotyped by using automatic IKAROS karyotyping software. In general, twenty metaphases from each specimen were analyzed as per the International System for Human Cytogenetic Nomenclature (ISCN) [10].

A dual colour FISH assay using Abbott Molecular Vysis Locus-specific identifier Eto and AML1 specific probes was performed on bone marrow cells. The ETO (RUNX1T1) was directly labeled with spectrum orange and RUNX1 (AML1) with spectrum green. The slides were hybridized overnight and subsequently analyzed. Microscopic evaluation of metaphases chromosome revealed a reciprocal translocation between $8 \mathrm{q} 22,19 \mathrm{q} 13$ and 21q22. Cytogenetic analysis of BM cells revealed an abnormal karyotype with a novel complex translocation involving chromosome 8,21,19 with the loss of $\mathrm{Y}$ chromosome, resulting in the karyotype $45, \mathrm{X},-\mathrm{Y}, \mathrm{t}(8 ; 19 ; 21)(\mathrm{q} 22 ; \mathrm{q} 13 ; \mathrm{q} 22)$ in all metaphases analyzed [Fig.1].

FISH analysis results showed that the cells had one orange signal corresponding to RUNX1T1(ETO) gene on chromosome 8, one green corresponding to RUNX1(AML1) gene on chromosome 21 and two yellow, orange, green fusion RUNX1T1/RUNX1 signals located on $\operatorname{der}(8)$ and $\operatorname{der}(21)$ [Fig.2].

\section{Discussion}

Complex cytogenetic variants of the classic translocation are uncommon in AML and it can exist in a small percentage of AML patients [5]. However, the $\mathrm{t}(8 ; 21)(\mathrm{q} 22 ; \mathrm{q} 22)$ which creates AML1/ETO fusion gene is a distinct type of transcript generally associated with favorable prognosis in the AMLM2 patient [1].

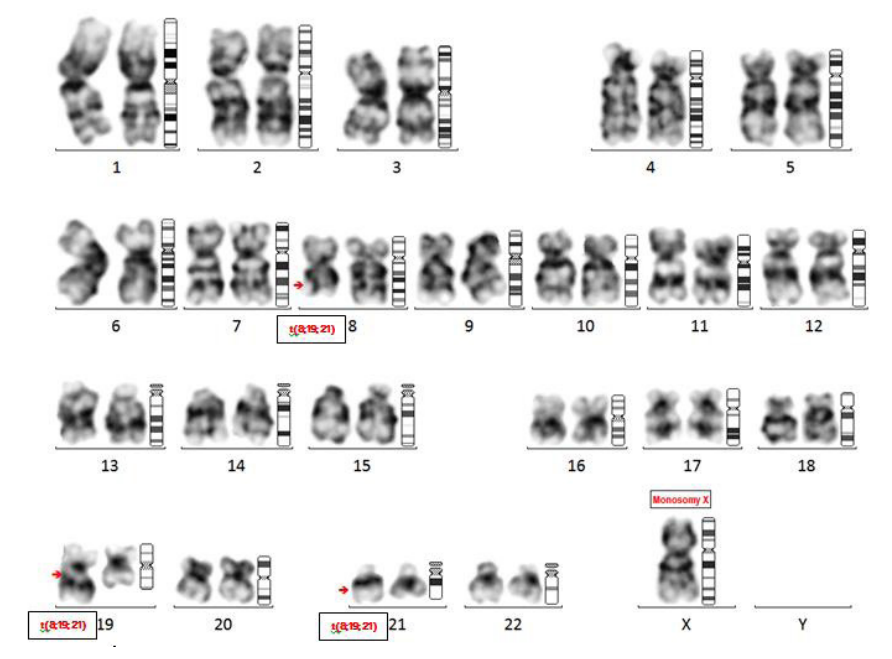

Fig 1: G-banded karyotype showing 45, X,-Y,t(8;19;21) (q22;q13;q22).

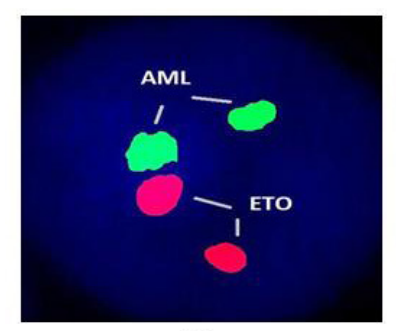

(a)

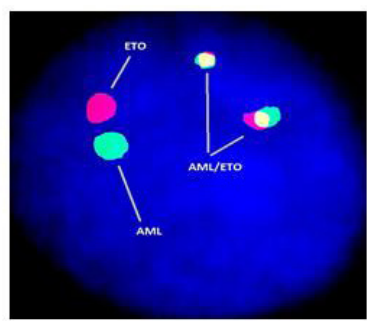

(b)
Fig 2: FISH analysis of bone marrow cells using LSI AML1/ ETO dual colour dual fusion probe showed (a) Negative image of AML1/ETO-two normal orange (ETO), two normal green (AML1) signals, (b) Positive image of AML1/ETO-one normal orange (ETO), one normal green (AML1) signals on normal chromosome 8 and 21, two orange and green showing yellow fusion signals on der8 and der 21 chromosomes. 
Brahmbutt et al. [11], suggested that the variants of $\mathrm{t}(9 ; 22)$ were observed in $5 \%$ cases of CML. Whereas, in AML variants of translocation $\mathrm{t}(8 ; 21)$ were observed in $3-4 \%$ of cases involving chromosome $1,2,4,5,6,7,8,10,12,13,15,17,18,19$ or $20[12,13]$. But the prognosis of this variants is contraversial [14]. However, Liu et al. [15], suggested that the there was no obvious differences between complex and typical $t(8 ; 21)$ with regards to remission rate and disease-free survival whereas, Gong et al. [16], suggested that the additional chromosome involved in the translocation could change the biological characteristic of the leukemic cells. Although the involvement of chromosome 19 with $t(8 ; 21)$ has been reported previously [7], the case reported here differs from previous reports in certain respects [17]. Interestingly this study reported by the Park et al. [7], suggested that the only two cases of three-way variants of $t(8 ; 21)$ involving chromosome 19 have been reported in AML as complex translocation which contains $8 \mathrm{q} 22,19 \mathrm{p} 13,21 \mathrm{q} 22$ region. They have also suggested that $19 \mathrm{q} 13$ breakpoint region was not reported previously but in the present study 19q13 breakpoint region in AML was found.

Furthermore, Farra et al. [2] pointed out that the $\mathrm{t}(8 ; 21)$ are reportedly associated with additional chromosomal abnormalities such as sex chromosome loss, trisomy 8 and structural aberrations involving 9q. The determination of the significance of variants is important because to assess the prognosis in terms of therapy outcome.

\section{Conclusion}

In conclusion, our study indicated that the conventional cytogenetic investigation is important for the rapid and precise diagnosis of $\mathrm{t}(8 ; 21)$. Translocation $\mathrm{t}(8 ; 19 ; 21)(\mathrm{q} 22 ; \mathrm{q} 13 ; \mathrm{q} 22)$ is a novel, rare but recurrent variant translocation of $t(8 ; 21)$. Due to the rarity of this translocation, future studies dealing with $\mathrm{t}(8 ; 21)$ variants are needed to evaluate clinical as well as prognostic and biological features and its significance.
Contributors: MVP: manuscript editing, and literature search; SNV: manuscript writing; PKG: critical inputs into the manuscript and experimental process. PKG will act as guarantor. All authors approved the final version of the manuscript.

Funding: None; Competing interests: None stated.

\section{References}

1. Ahmed F, Kokate P, Chheda P, Dalvi R, Das BR, Mandava S. Molecular Cytogenetic findings in a threeway novel of $\mathrm{t}(1 ; 8 ; 21)(\mathrm{p} 35 ; \mathrm{q} 22 ; \mathrm{q} 22)$ : a unique relocation of the AML/ETO fusion gene 1p35 in AMLM2. Cancer Genet Cytogenet. 2008;180:153-157.

2. Farra C, Awwad J, Valent A, Lozach F, Bernheim A. Complex translocation $(8 ; 12 ; 21)$ : a new variant of $\mathrm{t}(8 ; 21)$ in acute myeloid leukemia. Cancer Genet Cytogenet. 2004;155:138-142.

3. Xue Y, Niu C, Chen S, Wang Y, Guo Y, Cie X, et al. Two cases of AML (M2) with a $t(8 ; 19)(q 22 ; \mathrm{q} 13)$ : a new cytogenetic variant. Cancer Genet Cytogenet 2000;118:154-158.

4. Trivedi PJ, Brahmbhatt MM, Patel DM, Shukla SN, Patel PS. Acute myeloid leukemia with a masked type of three-way $\mathrm{t}(8 ; 11 ; 21)$ revealed by fluorescence in situ hybridizations using AML1-ETO probe. J Assoc Genet Technol. 2014;40:11-15.

5. Kakosaiou K, Daraki A, Zomas A, Manola KN. A novel variant translocation $\mathrm{t}(8 ; 16 ; 21)(\mathrm{q} 22 ; \mathrm{q} 24 ; \mathrm{q} 22)$ in acute myeloid leukemia expressing both myeloid and lymphoid markers. Hospital Chronicles. 2015;10:174176.

6. Grimwade D, Walker H, Harrison G, Oliver F, Chatters $\mathrm{S}$, Harrison CJ, et al. The predictive value of hierarchical cytogenetic classification in older adults with acute myeloid leukemia (AML): analysis of 1065 patients entered into the United Kingdom Medical Research Council AML11 trial. Blood. 2001;98:1312-1320.

7. Park TS, Song J, Lee KA, Kim J, Kim SJ, Lee JH, et al. Complex $\mathrm{t}(8 ; 19 ; 21)(\mathrm{q} 22 ; \mathrm{p} 13 ; \mathrm{q} 22)$ as a sole abnormality in a patient with de novo acute myeloid leukemia. Cancer Genet Cytogenet. 2008;185:109-112.

8. Xiao Z, Greaves MF, Buffler P, Smith MT, Segal MR, Dicks BM, et al. Molecular characterization of genomic AML1-ETO fusion in childhood leukemia. Leukemia. 2001;15:1906-1913.

9. Seabright M. A rapid banding technique for human chromosomes. Lancet. 1971;2:971-972.

10. Mitelman F. An international system for human cytogenetic nomenclature (ISCN): Recommendations of the international standing committee on human cytogenetic nomenclature. S. Karger, Basel, 1995. 
11. Brahmbhatt MM, Patel PS, Trivedi PJ, Beena PP, Sarju BG, Esha ND, et al. Unusual location of BCR/ ABL fusion gene in four CML patients with masked Philadelphia chromosome. International $\mathrm{J}$ Medical Science. 2010;2:38-43.

12. Nucifora G, Rowley JD. AML1 and the 8; 21 and 3; 21 translocations in acute and chronic myeloid leukemia. Blood. 1995;86:1-14.

13. Ishida F, Ueno M, Tanaka H, Makishima H, Suzawa $\mathrm{K}$, Hosaka $\mathrm{S}$, et al. $\mathrm{t}(8 ; 21 ; 14)(\mathrm{q} 22 ; \mathrm{q} 22 ; \mathrm{q} 24)$ is a novel variant of $\mathrm{t}(8 ; 21)$ with chimeric transcripts of AML1ETO in acute myelogenous leukemia. Cancer Genet Cytogenet. 2002;132:133-135.

14. Gmidène A, Sennana H, Frikha R, Elloumi M, Belaaj $\mathrm{H}$, Saad A. An unusual three-way translocation $\mathrm{t}(21 ; 8 ; 1)$ (q22;q22;q32) in a case of acute myeloid leukemia (M2). Ann Biol Clin. 2012;70:213-216.

15. Liu XP, Xue YP, Liu SH, Mi YC, Han MZ, Xiao ZJ, et al. An analysis of cytogenetic characteristics and prognosis of $189 \mathrm{t}(8 ; 21)$ acute myeloid leukemia patients. Chin J Intern Med. 2006;45:918-921.

16. Gong JY, Liu XP, Li CW, Zhao XC, Dai Y, Qin S, et al. Clinical and laboratory study of a complex translocation $\mathrm{t}(6 ; 21 ; 8)(\mathrm{p} 22 ; \mathrm{q} 22 ; \mathrm{q} 22)$ in two patients with acute myeloid leukemia. Zhonghua Xue Ye Xue Za Zhi. 2006;27:314-317.

17. Taguchi H, Kitagawa T, Yamashita M, Kubonishi I, Miyoshi I. New variant translocation $(1 ; 8 ; 21)$ in a case of acute myeloblastic leukemia (M2). Cancer Genet Cytogenet. 1986;23:219-223. 